\title{
Upper Extremity Muscle Strength in Children With Unilateral Spastic Cerebral Palsy
}

Citation for published version (APA):

Dekkers, K. J. F. M., Rameckers, E. A. A., Smeets, R. J. E. M., Gordon, A. M., Speth, L. A. W. M., Ferre, C. L., \& Janssen-Potten, Y. J. M. (2020). Upper Extremity Muscle Strength in Children With Unilateral Spastic Cerebral Palsy: A Bilateral Problem? Physical Therapy, 100(12), 2205-2216. https://doi.org/10.1093/ptj/pzaa155

Document status and date:

Published: 01/12/2020

DOI:

10.1093/ptj/pzaa155

Document Version:

Publisher's PDF, also known as Version of record

Document license:

Taverne

Please check the document version of this publication:

- A submitted manuscript is the version of the article upon submission and before peer-review. There can be important differences between the submitted version and the official published version of record.

People interested in the research are advised to contact the author for the final version of the publication, or visit the DOI to the publisher's website.

- The final author version and the galley proof are versions of the publication after peer review.

- The final published version features the final layout of the paper including the volume, issue and page numbers.

Link to publication

\footnotetext{
General rights rights.

- You may freely distribute the URL identifying the publication in the public portal. please follow below link for the End User Agreement:

www.umlib.nl/taverne-license

Take down policy

If you believe that this document breaches copyright please contact us at:

repository@maastrichtuniversity.nl

providing details and we will investigate your claim.
}

Copyright and moral rights for the publications made accessible in the public portal are retained by the authors and/or other copyright owners and it is a condition of accessing publications that users recognise and abide by the legal requirements associated with these

- Users may download and print one copy of any publication from the public portal for the purpose of private study or research.

- You may not further distribute the material or use it for any profit-making activity or commercial gain

If the publication is distributed under the terms of Article $25 \mathrm{fa}$ of the Dutch Copyright Act, indicated by the "Taverne" license above, 


\section{Original Research}

\section{Upper Extremity Muscle Strength in Children With Unilateral Spastic Cerebral Palsy: A Bilateral Problem?}

Koen J.F.M. Dekkers, Eugene A.A. Rameckers, Rob J.E.M. Smeets, Andrew M. Gordon, Lucianne A.W.M. Speth, Claudio L. Ferre, Yvonne J.M. Janssen-Potten

Objective. The objective was to investigate whether muscle strength in the nonaffected and affected upper extremities (UEs) in children (7-12 years) with unilateral spastic cerebral palsy (USCP) differs from that in children with typical development (TD).

Methods. A cross-sectional study design was used. Isometric arm strength (wrist flexion, wrist extension with flexed and extended fingers, elbow flexion/extension) was assessed in 72 children (mean age $=9.3[\mathrm{SD}=1.9]$ years) with USCP, and isometric grip/pinch strength was assessed in 86 children (mean age $=9.3[\mathrm{SD}=1.8]$ years) with USCP. Arm/grip/pinch strength was assessed in 120 children (mean age $=9.5[\mathrm{SD}=1.7]$ years) with TD. Arm strength was measured with a hand-held dynamometer, and grip/pinch strength was measured with a calibrated, modified (digitized) grip dynamometer and a pinch meter. The nonaffected UE of children with USCP was compared with the preferred UE of children with TD because both sides represent the preferred UE. The affected UE was compared with the nonpreferred UE of children with TD, as both sides represent the nonpreferred UE.

Results. In all measurements except for grip strength of the preferred UE, children with USCP were weaker than children with TD.

Conclusions. In children with USCP, muscle strength weakness exists in both UEs.

Impact. When unimanual or bimanual ability limitations are present in children with unilateral cerebral palsy, investigation of the muscle strength of the nonaffected UE should be part of the assessment.

K.J.F.M. Dekkers, PT, Revant Rehabilitation Centers, Revant Centre Breda, Brabantlaan 1, $4817 \mathrm{JW}$ Breda, the Netherlands; Department of Rehabilitation Medicine, Research School CAPHRI, Maastricht University, Maastricht, the Netherlands; and University for Professionals for Pediatric Physical Therapy, AVANSplus, Breda, the Netherlands. Address all correspondence to Mr Dekkers at: k.dekkers@revant.nl.

E.A.A. Rameckers, PT, PhD, Department of Rehabilitation Medicine, Research School CAPHRI, Maastricht University; University for Professionals for Pediatric Physical Therapy, AVANSplus; Adelante Centre of Expertise in Rehabilitation and Audiology, Hoensbroek, the Netherlands; and Pediatric Rehabilitation, Biomed, Faculty of Medicine and Health Science, Hasselt University, Hasselt, Limburg, Belgium.

R.J.E.M. Smeets, MD, PhD,

Department of Rehabilitation Medicine, Research School CAPHRI, Maastricht University; and CIR Revalidatie, Eindhoven, the Netherlands.

A.M. Gordon, PhD, Department of Biobehavioral Sciences, Teachers College, Columbia University, New York, New York.

L.A.W.M. Speth, MD, PhD, Department of Rehabilitation Medicine, Research School CAPHRI, Maastricht University; and Adelante Centre of Expertise in Rehabilitation and Audiology.

C.L. Ferre, PhD, Department of Occupational Therapy, Boston University, Boston, Massachusetts.

Y.J.M. Janssen-Potten, PhD, Department of Rehabilitation Medicine, Research School CAPHRI, Maastricht University; and Adelante Centre of Expertise in Rehabilitation and Audiology.

[Dekkers KJFM, Rameckers EAA, Smeets RJEM, et al. Upper extremity muscle strength in children with unilateral spastic cerebral palsy: a bilateral problem? Phys Ther. 2020;100:2205-2216.]

(c) The Author(s) 2020. Published by Oxford University Press on behalf of the American Physical Therapy Association. All rights reserved. For permissions, please email: journals.permissions@oup.com

Published Ahead of Print:

August 28, 2020

Accepted: August 18, 2020 Submitted: August 19, 2019 


\section{Bilateral Strength Problems in Unilateral CP}

U nilateral spastic cerebral palsy (USCP) is characterized by motor impairments lateralized to 1 body side, resulting in an "affected" body side and a "nonaffected" body side. ${ }^{1-3}$ Several studies have shown that muscle strength of the affected upper extremity (UE) is considerably impaired compared with the nonaffected UE and compared with the UE strength of children with typical development (TD). ${ }^{4-6}$ Muscle strength weakness of the affected UE is one of the motor impairments affecting manual abilities. ${ }^{6,7}$

Several magnetic resonance imaging (MRI) studies in children with supposed USCP have shown bilateral brain lesions. ${ }^{8-11}$ Also, many clinicians perceive problems in the "nonaffected body side," and often this body side is appropriately referred to as the "less-affected body side." However, only a few studies have described possible impairments of the nonaffected body side or found reduced performance of the nonaffected UE in children with cerebral palsy compared with children with TD. ${ }^{12-15}$

Whether muscle strength weakness in the more-affected $\mathrm{UE}$ is the cause of this reduced performance is unclear, and one should keep in mind that these differences can also be attributed to problems with speed and/or coordination. So far, only 2 studies have investigated the muscle strength of the nonaffected hand in children with USCP, with opposite conclusions. One study showed that grip strength of the nonaffected hand of the children with USCP was, on average, $12 \%$ weaker compared with a group of children with TD. ${ }^{12}$ Another study found no significant differences between grip/pinch strength of the nonaffected hand of children with USCP compared with norm values of children with TD. ${ }^{14}$ Both studies only investigated grip/pinch strength, and studies on the strength of the nonaffected forearm and upper arm muscles are lacking. Hand strength is important for executing fine motor activities, but also the strength of upper and lower arm muscles is important during gross motor UE activities, such as lifting and carrying objects. It is therefore important to assess whether muscle weakness in the nonaffected UE is present, as this might have consequences when selecting the proper assessment/treatment to map/improve UE function.

Research on this topic has been done among adults after unilateral stroke, with several studies reporting motor impairments in the nonaffected UE in adults after unilateral stroke. ${ }^{16-23}$ Although these motor impairments are substantially less severe than in the affected UE, they can produce significantly limiting (bilateral) functional impairments, including problems performing the activities of daily living. ${ }^{24-26}$

In more than 50 articles, most of which focused on activities involving the lower limb of adults with unilateral stroke, muscle strength appeared to be related to functional activity performance. ${ }^{27}$ Such a relationship was also demonstrated for the upper limb, ${ }^{28}$ and it has been proven that strengthening interventions not only improve muscle strength but also activity after stroke. ${ }^{29}$

Although the cause for both USCP and stroke originates in the brain, the body functions in children with USCP have hardly developed at the time the brain injury/malformation occurs. Because children with USCP only use their nonaffected UE spontaneously in daily activities, ${ }^{30,31}$ the nonaffected UE is maximally stimulated during development. Adults who have had a stroke used both hands normally before the stroke occurred.

Therefore, it cannot simply be concluded that the findings in adults with stroke also apply to children with cerebral palsy.

The aim of this study was to investigate whether muscle strength in the "nonaffected" UE in children with USCP differs from children with TD. As prior studies that assessed the strength of the affected side used small sample sizes and/or only studied hand strength and/or used a measurement instrument that shows wide grading values when applied in children with moderate to good muscle strength, ${ }^{4-6}$ the muscle strength of the affected UE is also examined within this study.

\section{Methods}

\section{Study Design}

All data were obtained according to a cross-sectional study design. Data were collected in the Netherlands and the United States from 2009 to 2017.

The nonaffected UE of children with USCP was compared with the preferred UE of children with TD because both sides represent the preferred UE. The affected UE was compared with the nonpreferred UE of children with TD, as both sides represent the nonpreferred UE.

\section{Participants}

Permission was granted by the Medical Ethical Board of the Maastricht University Medical Center and Maastricht University, Maastricht, the Netherlands (METC azM/UM; trial number NL45430.068.1) and by Teachers College, Columbia University, New York, NY (USA).

For the children with USCP, muscle strength values were obtained from a study on the reliability of maximum isometric arm and grip/pinch strength measurements. ${ }^{32}$ Within this study population, the sample sizes for arm and grip/pinch strength varied due to the availability of the children and/or measurement instruments at the facilities. Children were recruited from 4 different Dutch rehabilitation centers and related schools for special education: Adelante Rehabilitation Center, Valkenburg; Libra Rehabilitation and Audiology, Tilburg; Revant Rehabilitation Centers, Breda and Goes; and Tolbrug 
Rehabilitation Center, Den Bosch. In the United States, the children with USCP were a convenience sample of children participating in an ongoing intensive UE training program at Teachers College, Columbia University. To be included, the child had to be diagnosed with USCP and aged between 7 and 12 years. The child also had to be classified as Gross Motor Function Classification System ${ }^{33}$ level I or II and Manual Ability Classification System $(\mathrm{MACS})^{34}$ level I, II, or III. All participants were capable of following simple instructions. A child was excluded when he/she had surgery or botulinum toxin A treatment in the $\mathrm{UE}$ in the past 6 months.

The children with TD were recruited in the Netherlands. Primary schools in different regions, both in cities and the countryside, were approached to participate in this research. After informed consent of the management of the school, children were selected at random and invited to participate in this study. After informed consent had been received from their parents (and from the children who were 12 years old), the children were invited for the measurements.

\section{Procedure}

The measurements took place in the child's own environment: the rehabilitation center for the children with USCP, and primary school for the children with TD.

A standardized protocol with detailed descriptions of all procedures and measurements was used. Prior to testing, body weight and height, MACS, and Gross Motor Function Classification System level (for the children with USCP) were determined. All children performed 1 set of strength measurements, consisting of isometric arm strength (IAS) with the hand-held dynamometer (HHD) and isometric grip/pinch strength (IGPS) with the E-Link evaluation system (see Measures for a description). The sequence of strength measurements was randomized. Both UEs were measured successively, with the preferred UE being tested before the nonpreferred UE.

The HHD and E-Link measurements were performed 3 consecutive times, and the mean of the 3 measurements was calculated. In this way, variation in muscle strength due to variations in placing the measurement instrument near the described measurement spot was minimized. Between each measurement, the child had at least 30 seconds of rest, leaving sufficient time for the muscles to recover.

Test scores were read by the therapist and registered by the same therapist on a test form. For the E-Link evaluation system, test scores were also stored on the E-Link evaluation system computer.

All measurements were performed by 10 different assessors having no direct professional relationship with the participants. Two of the assessors (K.J.F.M.D., E.A.A.R.) involved during the entire project were experienced pediatric research physical therapists. The other 8 assessors involved in the study for 6 months were master's students in pediatric physical therapy. Each assessor received 4 hours of training from K.J.F.M.D. or E.A.A.R. regarding use of the standardized protocol.

\section{Measurements}

The child was seated in an upright position on a chair with back support and armrests. The armrests of the chair were used to support the arms during testing. The initial posture was a neutral position $\left(0^{\circ}\right)$ of the wrist joint and 90 degrees of flexion of the elbow joint. For elbow extension, the initial posture was adjusted so that the lower arm could move and elbow extension was possible. If a child was unable to perform the test, the result of the measurement was not used in the analysis.

Isometric arm strength. Maximum isometric muscle strength of the wrist extension with extended fingers, wrist extension with flexed fingers, wrist flexion, and elbow flexion/extension were measured with the MicroFET2 HHD (Hoggan Scientific LLC, Salt Lake City, UT, USA). The HHD is an electronic device that fits in the palm of the hand of the assessor. A load cell (strain gauge technology) measures the isometric muscle strength applied to a transducer. The "make method," in which the child applies force against a fixed HHD, was used. ${ }^{35}$ The applied force was measured in newtons. Children were encouraged by the therapist to produce maximum force. Reliability of the measurements for children with USCP is excellent. ${ }^{32}$

Isometric grip/pinch strength. The IGPS was measured with the Biometric E-Link evaluation system (Biometrics Ltd, Gwent, UK), a calibrated, computerized system that incorporates a modified (digitized) grip dynamometer and a pinch meter. The applied force was measured in $0.1 \mathrm{~kg}$ increments. The handle position of the E-Link handgrip was adapted to the child's hand size according to the E-Link guidelines for positioning. The child was also asked where the position of the handle felt the best. When there was uncertainty, other handle positions were tried. Children were encouraged by the therapist to produce maximum force. Reliability of the measurements in children with USCP is excellent. ${ }^{32}$

\section{Data Analysis}

All statistical analyses were performed using $\mathrm{R}$ (The $\mathrm{R}$ Foundation, https://www.r-project.org/foundation); the script used for analyses is available as a Supplementary File.

Participant characteristics. Descriptive statistics including means, SDs, and confidence intervals were used to summarize participant characteristics and strength 


\section{Bilateral Strength Problems in Unilateral CP}

measurements by age and group (children with USCP or children with TD). Independent-sample $t$ tests were used to compare baseline characteristics.

IAS (HHD). Exploratory analyses revealed positive correlations between measures of arm strength in the 5 different positions (wrist extension with extended fingers, wrist extension with flexed fingers, wrist flexion, elbow flexion, elbow extension). Rather than analyzing each outcome separately, and in order to avoid type I errors, a multivariate analysis of variance (MANOVA) was performed on the 5 variables (as a matrix of dependent variables), with age, sex, group, and an age $\times$ group interaction as independent variables. A separate MANOVA was performed for the preferred UE and the nonpreferred UE.

Given that MANOVA does not permit specification of how the combination of dependent variables differ between groups, linear discriminant analysis (LDA) was performed as a follow-up. LDA is a dimensionality reduction technique that can be used to characterize 2 or more classes/categories. For these analyses, we used LDA to examine which variables best distinguished between the 2 groups (children with USCP and children with TD).

IGPS (E-Link). The analysis for grip and pinch strength involved 4 generalized linear models that were fit using a Gaussian distribution with an identity link. The models were separately fit to evaluate the difference between groups for grip strength of the preferred UE, pinch strength of the preferred UE, grip strength of the nonpreferred UE, and pinch strength of the nonpreferred UE. Age, sex, and an age $\times$ group interaction were also included in the models to adjust for their potential impact, with the associations between age and strength assumed to be linear. In our specific analysis, the group children with USCP was set as the reference group. Thus, the parameter estimate for group is the difference between the group of children with TD relative to the group of children with USCP when adjusted for age, sex, and age $\times$ group interaction. Given the possibility of heteroscedasticity, robust standard errors were computed for the parameter estimates using generalized estimating equations with an independent correlation structure. $P$ values were computed using the Wald statistic.

\section{Role of the Funding Source}

The funders had no role in the design, the data collection, analysis, and interpretation, the reporting of this work, or the decision to submit the work for publication.

\section{Results}

Participant characteristics for sex, age, height, weight, preferred/nonpreferred side, and MACS levels (for children with USCP) are provided in Table 1.
All children were able to perform the measurements. For children with USCP, muscle strength values of 72 children for the IAS measurements and 86 children for the IGPS measurements were taken. For the children with TD, a total of 120 children were included in all measurements. There were no significant differences between the groups in age (USCP-IAS/TD: $P=.53$; USCP-IGPS/TD: $P=.56$ ), height (USCP-IAS/TD: $P=.07$; USCP-IGPS/TD: $P=.06$ ), or weight (USCP-IAS/TD: $P=.93$; USCP-IGPS/TD: $P=.88)$.

\section{Isometric Arm Strength}

Preferred UE. The means and differences in arm muscle strength are presented in Table 2 . Table 3 provides the parameter estimates for the MANOVA. For the preferred UE, children with USCP were consistently weaker than children with TD. A significant interaction between age and group suggested that differences between the 2 groups were not constant across the age groups for the combined dependent variables $\left(F_{5,183}=2.49 ; P<.05\right.$; Pillai trace $=0.063$ ). Across the age groups, the difference in muscle strength of the elbow flexors and elbow extensors appears to change most between children with USCP and children with TD. It is remarkable that at the age of 7 , the group of children with USCP is stronger in elbow flexion and elbow extension than the group of children with TD. At the age of 12, the group of children with TD is stronger in these muscle groups compared with the group of children with USCP.

Discriminant analysis was used to determine if the 5 measurements of IAS differentiated between children with USCP and children with TD. Table 3 provides a summary of the linear discriminant function coefficients associated with each measurement. Wrist extension, wrist extension with fingers flexed, and elbow extension provided the greatest contribution to group separation. Figure 1 demonstrates the group separation using the values of the discriminant function for the group of children with USCP and group of children with TD. Despite differences between the 2 groups, there is some degree of overlap in the distributions.

Nonpreferred UE. For the nonpreferred UE, children with USCP were consistently weaker than children with TD. Table 3 provides the parameter estimates for the MANOVA. There was a significant interaction between age and group, suggesting that differences between the 2 groups are not constant across the age groups for the combined dependent variables $\left(F_{5,183}=5.14 ; P<.001\right.$; Pillai trace $=0.12$ ). Across the age groups (young to old), the difference between the 2 groups changes the most for elbow flexion and elbow extension.

Table 3 provides a summary of the linear discriminant function coefficients associated with each measurement 
Table 1.

Description of the Participants

\begin{tabular}{|c|c|c|c|c|}
\hline \multirow{2}{*}{ Characteristic and Measurement } & \multirow{2}{*}{ Age Group (y) } & \multicolumn{3}{|c|}{ No. of Participants } \\
\hline & & Total & Boys & Girls \\
\hline \multicolumn{5}{|c|}{ Isometric arm strength (measured with HHD) in children with USCP } \\
\hline $\begin{array}{l}\text { No. of participants }=72 \text { ( } 45 \text { boys; } 27 \text { girls }) \\
\text { Age, mean }(S D)=9 \text { y } 3 \text { mo }(1 \text { y } 9 \text { mo })\end{array}$ & 7 & 17 & 9 & 8 \\
\hline \multirow{2}{*}{$\begin{array}{l}\text { Affected side (no. of participants) } \\
\text { Right }=45 \\
\text { Left }=27\end{array}$} & 8 & 12 & 5 & 7 \\
\hline & 9 & 12 & 9 & 3 \\
\hline \multirow{2}{*}{$\begin{array}{l}\text { MACS level (no. of participants) } \\
\text { Level I }=23 \\
\text { Level II }=42 \\
\text { Level III }=7\end{array}$} & 10 & 8 & 5 & 3 \\
\hline & 11 & 7 & 5 & 2 \\
\hline Weight, $\mathrm{kg}$, mean $(\mathrm{SD})=37.2(10.2)$ & 12 & 16 & 12 & 4 \\
\hline \multicolumn{5}{|c|}{ Isometric grip and pinch strength (measured with E-Link system) in children with USCP } \\
\hline \multirow{6}{*}{$\begin{array}{l}\text { No. of participants = } 86 \text { (53 boys; } 33 \text { girls) } \\
\text { Age, mean (SD) =9 y } 3 \text { mo (1 y } 8 \text { mo) } \\
\text { Affected side } \\
\text { Right }=51 \\
\text { Left }=35 \\
\text { MACS level } \\
\text { Level I = } 29 \\
\text { Level II }=47 \\
\text { Level III }=10 \\
\text { Height, } \mathrm{cm} \text {, mean (SD) }=139(12.2) \\
\text { Weight, } \mathrm{cm} \text {, mean }(\mathrm{SD})=37.0(10.1)\end{array}$} & 7 & 19 & 10 & 9 \\
\hline & 8 & 14 & 6 & 8 \\
\hline & 9 & 17 & 11 & 6 \\
\hline & 10 & 9 & 5 & 4 \\
\hline & 11 & 11 & 9 & 2 \\
\hline & 12 & 16 & 12 & 4 \\
\hline \multicolumn{5}{|l|}{ Children with TD (all measurements) } \\
\hline \multirow{6}{*}{$\begin{array}{l}\text { No. of participants = } 120 \text { ( } 60 \text { boys; } 60 \text { girls) } \\
\text { Age, mean (SD) }=9 \text { y } 5 \text { mo (1 y } 7 \text { mo) } \\
\text { Preferred side } \\
\text { Right }=106 \\
\text { Left }=14 \\
\text { Height, } \mathrm{cm} \text {, mean (SD) }=143(12.6) \\
\text { Weight, } \mathrm{kg} \text {, mean (SD) }=37.4(11.6)\end{array}$} & 7 & 20 & 10 & 10 \\
\hline & 8 & 20 & 10 & 10 \\
\hline & 9 & 20 & 10 & 10 \\
\hline & 10 & 20 & 10 & 10 \\
\hline & 11 & 20 & 10 & 10 \\
\hline & 12 & 20 & 10 & 10 \\
\hline
\end{tabular}

${ }^{a} \mathrm{HHD}=$ hand-held dynamometer; MACS = Manual Ability Classification; TD = typical development; USCP = unilateral spastic cerebral palsy.

for the nonpreferred UE. Wrist extension with fingers flexed and wrist flexion provided the greatest contribution to group separation. Figure 1 demonstrates the group separation using the values of the discriminant function for the group children with USCP and group children with TD. For most cases, there appears to be clear separation between the 2 groups.

\section{Isometric Grip/Pinch Strength}

The means and differences in grip and pinch strength are presented in Table 2 . For 3 of the 4 measurements, analysis of grip/pinch strength resulted in statistically significant group differences. Table 4 summarizes the results for the fitted models. For pinch strength of the preferred UE, pinch strength of the nonpreferred UE, and grip strength of the nonpreferred UE, children with TD on average showed higher scores when controlling for age and sex. In addition, for grip strength of the nonpreferred UE, there was a significant age by group interaction with children with TD showing greater gains in strength over time (Fig. 2).

\section{Discussion}

The aim of this study was to investigate whether the UE muscle strength between children with USCP and the 


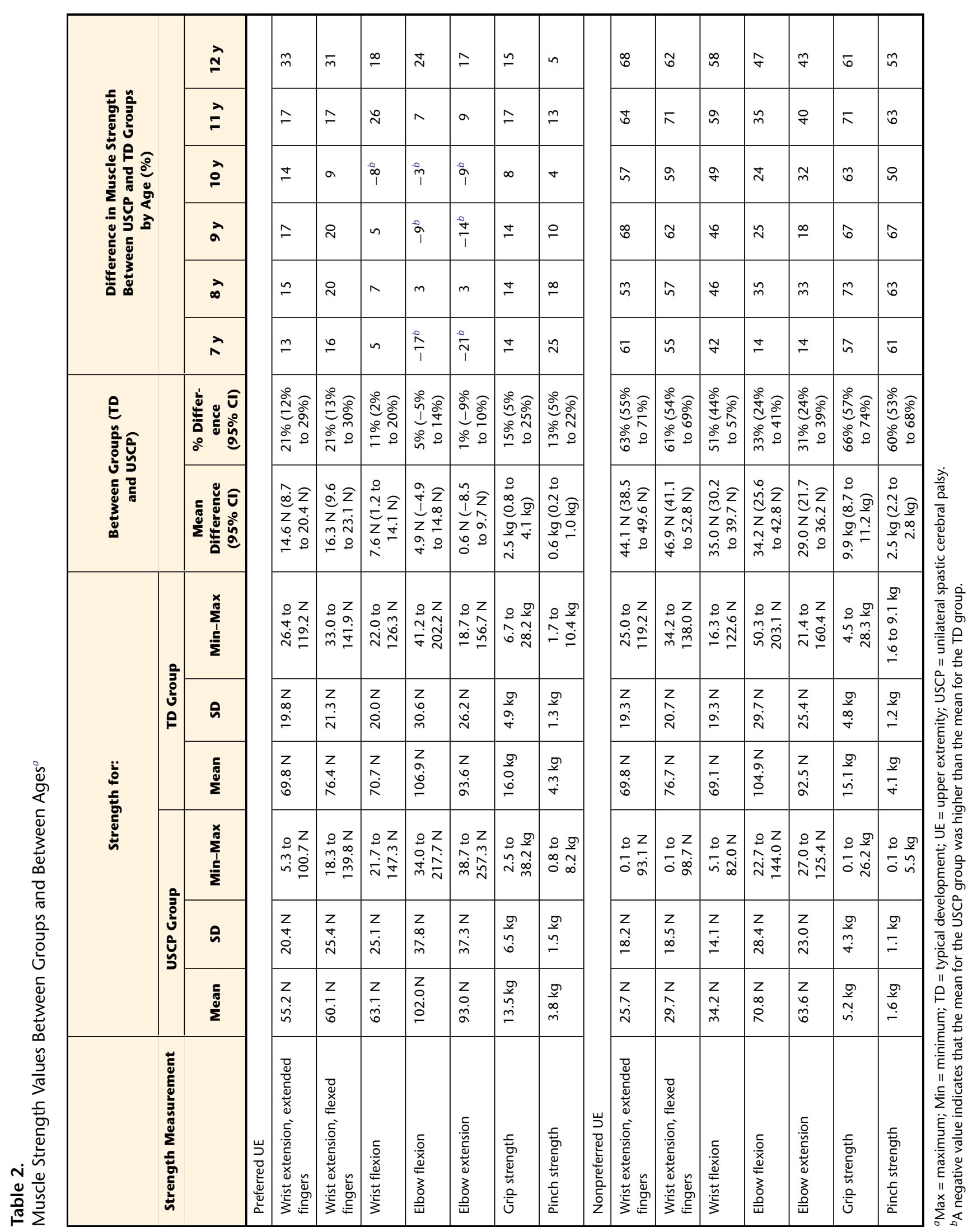


Table 3.

Results from MANOVA and LDA of Isometric Arm Strength ${ }^{a}$

\begin{tabular}{|c|c|c|c|c|c|}
\hline UE & Variable & Pillai Trace & Approximate $F$ & $\boldsymbol{P}^{b}$ & $\begin{array}{c}\text { Discriminant Function } \\
\text { Coefficient }^{c}\end{array}$ \\
\hline \multirow[t]{9}{*}{ Preferred } & USCP vs TD (group) & 0.23 & 10.83 & $<.001$ & \\
\hline & Age & 0.30 & 15.53 & $<.001$ & \\
\hline & Sex & 0.02 & 0.75 & .586 & \\
\hline & Age $\times$ group interaction & 0.06 & 2.49 & $<.05$ & \\
\hline & Wrist extension & & & & 0.031 \\
\hline & $\begin{array}{l}\text { Wrist extension (fingers } \\
\text { flexed) }\end{array}$ & & & & 0.033 \\
\hline & Wrist flexion & & & & 0.013 \\
\hline & Elbow flexion & & & & -0.008 \\
\hline & Elbow extension & & & & -0.030 \\
\hline \multirow[t]{9}{*}{ Nonpreferred } & USCP vs TD (group) & 0.68 & 78.92 & $<.001$ & \\
\hline & Age & 0.30 & 15.80 & $<.001$ & \\
\hline & Sex & 0.01 & 0.34 & .888 & \\
\hline & Age $\times$ group interaction & 0.12 & 5.14 & $<.001$ & \\
\hline & Wrist extension & & & & 0.019 \\
\hline & $\begin{array}{l}\text { Wrist extension (fingers } \\
\text { flexed) }\end{array}$ & & & & 0.029 \\
\hline & Wrist flexion & & & & 0.032 \\
\hline & Elbow flexion & & & & -0.009 \\
\hline & Elbow extension & & & & -0.012 \\
\hline
\end{tabular}

${ }^{a} \mathrm{LDA}=$ linear discriminant analysis; MANOVA = multivariate analysis of variance; TD = typical development; UE = upper extremity; USCP = unilateral spastic cerebral palsy.

${ }^{b} P$ value from MANOVA analysis.

'Bolded values are variables that likely contributed the most to group separation in the LDA.

children with TD differs for both the PUE and the nonpreferred UE.

\section{Muscle Strength in the Preferred UE}

Overall, children with USCP were consistently weaker than children with TD in their preferred UE, except for grip strength. These findings are almost consistent with the findings in adults with stroke. Impairments in strength of the total UE were found in adults with stroke. ${ }^{19,23}$

Muscle weakness of the preferred UE of children with USCP seems to go beyond impairments in the hand. It is striking that the muscle strength of the elbow flexion and extension in the younger age groups is higher in children with USCP than in children with TD. In the older age groups, this difference between groups is reversed. A possible explanation could be the intensive (bimanual) training in children with USCP at the younger age and more disuse of the preferred UE at the older age. More research to explain this result is needed.
Rich et $\mathrm{al}^{12}$ and Tomhave et $\mathrm{al}^{14}$ assessed only differences in grip and pinch strength, so the results of these 2 strength measurements can be compared. The results of our study regarding grip strength are comparable with the results of Tomhave et $\mathrm{al}^{14}$ but different from those of Rich et $\mathrm{al}^{12}$ In the study by Rich et al, older children (8-18 years old; mean $=14.1[\mathrm{SD}=2.4]$ years $)$ were included. ${ }^{12}$ As Figure 2 shows, the differences in grip strength become larger in the older age groups. This could explain why the differences in grip strength between the groups is probably not yet clear in our population.

Our findings regarding the difference in pinch strength contradict the study of Tomhave et al (similar mean value compared with norm value). ${ }^{14}$ Although all studies use the average of 3 measurements to determine the muscle strength, some differences in methodology exist that may explain these discrepancies.

A different measurement instrument was used to measure grip strength: the digitized Biometric E-Link evaluation system (Biometrics Ltd, Gwent, UK) in our study versus a 


\section{Bilateral Strength Problems in Unilateral CP}

Preferred Upper Extremity
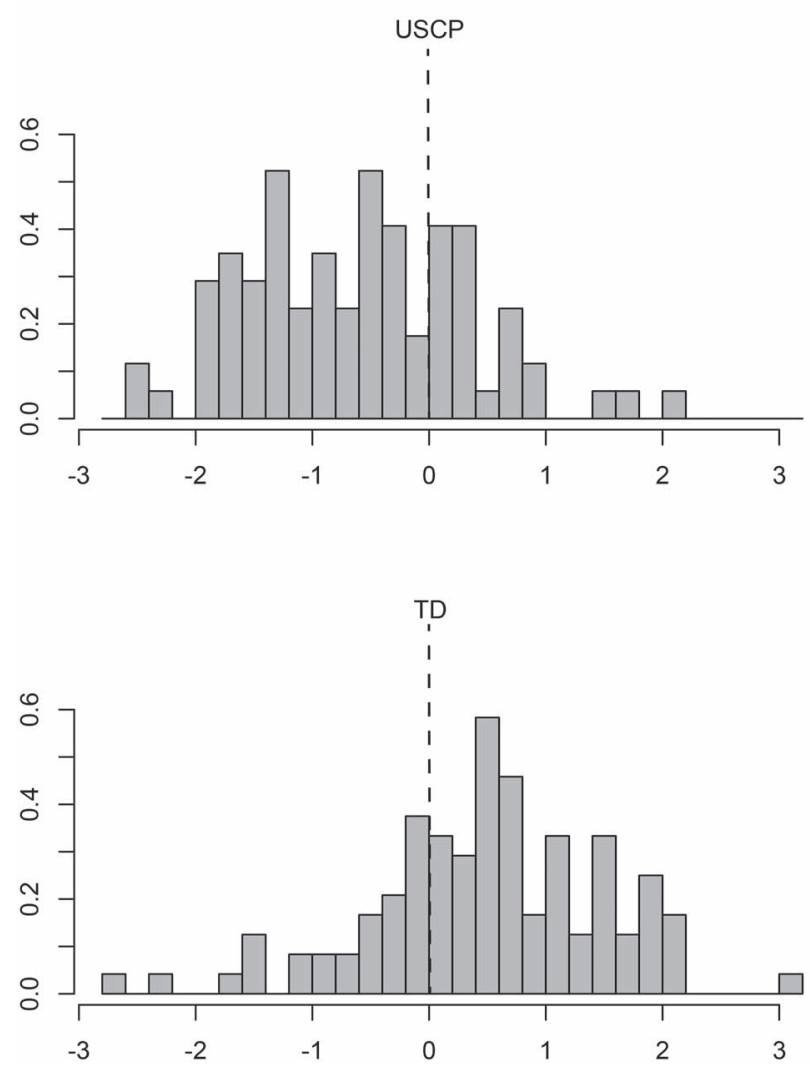

Non-preferred Upper Extremity
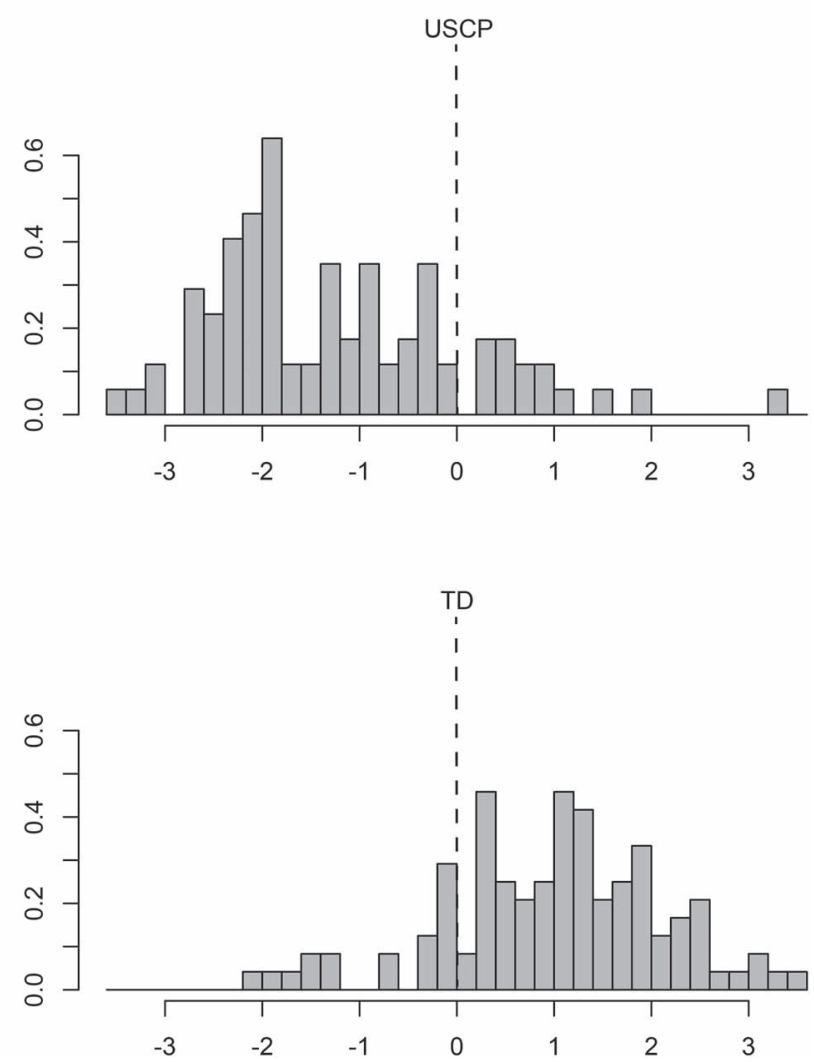

Figure 1.

Group separation is shown using the values of the discriminant function for the group of children with USCP and group of children with TD. Despite differences between the 2 groups, there is also a degree of overlap in the distributions.

Jamar hydraulic hand dynamometer (Patterson Medical, Warrenville, IL, USA) in the other studies. ${ }^{12,14}$ The Biometric E-Link system has (digitized) incremental steps of $0.1 \mathrm{~kg}$, whereas the Jamar hydraulic dynamometer has (visual) incremental steps of $2 \mathrm{~kg} / 5 \mathrm{lb}$. Therefore, small differences in muscle strength are more likely to be detected using our E-Link system.

In our study and in the study by Rich et al, ${ }^{36}$ children with TD were used as controls, but Tomhave et $\mathrm{al}^{14}$ compared the hand strength of children with USCP with previously published norms. These norms were based on 199 Brazilian children recruited within the same area and divided into 10 age/sex groups. ${ }^{37}$ About $37 \%$ of the American children were overweight or obese, whereas in Brazil this percentage was about $16 \%$ to $20 \% .^{38,39}$ Within the Netherlands, this percentage was about $12 \% .^{40}$ As increasing weight status is associated with improved grip strength, ${ }^{38}$ it is unclear whether the norm population sufficiently resembled the total population of children within the United States and the Netherlands.

Regarding our results, in most measurements the group of children with USCP showed a larger range of muscle strength compared with children with TD. These results cannot be compared with the other studies because this information is not available. With this larger range in muscle strength, it is expected that specific characteristics related to children with USCP, such as MACS level and/or location of the lesion, may have an impact on muscle weakness. However, due to the small subgroups (eg, there are only 7-9 children with MACS level III), a comparison of muscle strength values for different MACS levels was not possible between children with TD and children with USCP.

Because there was no information on the overall activity and participation levels of the children with USCP, there is a chance that reduced overall activity and participation levels might have affected the hand function of the nonaffected UE.

Unfortunately, MRIs or neurophysiological data for the children with USCP were not available, so we could not examine whether the muscle weakness in children with USCP is related to a specific brain damage location. In 
Table 4.

Results from GLM of Grip and Pinch Strength ${ }^{a}$

\begin{tabular}{|c|c|c|c|c|}
\hline Upper Extremity & Variable & Estimate & SE & $\boldsymbol{P}^{b}$ \\
\hline \multirow[t]{12}{*}{ Preferred } & \multicolumn{4}{|l|}{ Pinch strength, kg } \\
\hline & Intercept $^{C}$ & 2.88 & 0.23 & $<.001$ \\
\hline & TD relative to USCP & 0.76 & 0.29 & $<.01$ \\
\hline & $1-y$ increase in age & 0.43 & 0.07 & $<.001$ \\
\hline & Female relative to male & -0.28 & 0.17 & .08 \\
\hline & Age $\times$ group interaction & -0.09 & 0.10 & .41 \\
\hline & \multicolumn{4}{|l|}{ Grip strength, kg } \\
\hline & Intercept $^{c}$ & 9.74 & 0.85 & $<.001$ \\
\hline & TD relative to USCP & 1.35 & 1.07 & .21 \\
\hline & $1-y$ increase in age & 1.76 & 0.27 & $<.001$ \\
\hline & Female relative to male & -0.68 & 0.64 & .29 \\
\hline & Age $\times$ group interaction & 0.38 & 0.36 & .30 \\
\hline \multirow[t]{12}{*}{ Nonpreferred } & \multicolumn{4}{|l|}{ Pinch strength, kg } \\
\hline & Intercept $^{c}$ & 1.23 & 0.20 & $<.001$ \\
\hline & TD relative to USCP & 2.14 & 0.25 & $<.001$ \\
\hline & $1-y$ increase in age & 0.19 & 0.06 & $<.01$ \\
\hline & Female relative to male & -0.12 & 0.15 & .44 \\
\hline & Age $\times$ group interaction & 0.14 & 0.09 & .12 \\
\hline & \multicolumn{4}{|l|}{ Grip strength, kg } \\
\hline & Intercept $^{c}$ & 4.72 & 0.72 & $<.001$ \\
\hline & TD relative to USCP & 6.79 & 0.90 & $<.001$ \\
\hline & $1-y$ increase in age & 0.67 & 0.23 & $<.05$ \\
\hline & Female relative to male & -0.21 & 0.54 & .7 \\
\hline & Age $\times$ group interaction & 1.24 & 0.31 & $<.001$ \\
\hline
\end{tabular}

${ }^{a} \mathrm{GLM}=$ generalized linear model; TD = typical development; USCP = unilateral spastic cerebral palsy.

${ }^{b} P$ values were calculated using the Wald statistic.

${ }^{c}$ The model was centered on the age variable (the intercept represented the mean at an age of 7 y) with the USCP group set as the reference group.

addition, it is not known how much of the deficit might be due to bilateral involvement of the brain.

\section{Muscle Strength in the Nonpreferred UE}

In the nonpreferred UE, the children with USCP produced statistically significantly lower muscle strength values for all measures compared with children with TD. These differences in muscle strength are in accord with other studies. ${ }^{4,5}$ Our study confirms the hypothesis that children with USCP can generate less muscle strength with the nonpreferred side compared with children with TD. However, it is remarkable that the percentage difference in muscle strength is less in the proximal UE muscle groups compared with the distal UE muscle groups. A possible explanation is that the severity of hand function is closely related to the integrity and organization of direct corticospinal projections to the hand muscles and that these largely control distal movement/force. ${ }^{41}$ A second explanation might be that because most children with USCP only use the nonpreferred UE to support the preferred UE, the proximal muscle groups may be used more compared with the distal (fine motor) muscle groups.

\section{Limitations}

We used a cross-sectional study design to compare differences in muscle strength between both groups. However, it should be noted that we did not study changes in muscle strength within each individual child. To do so, a longitudinal study design is more appropriate, but such studies are logistically challenging to execute.

Because the age of our study population ranges from 7 to 12 years, these results cannot be extrapolated to other age groups. The children with USCP are American and Dutch whereas the children with TD were exclusively Dutch 


\section{Bilateral Strength Problems in Unilateral CP}
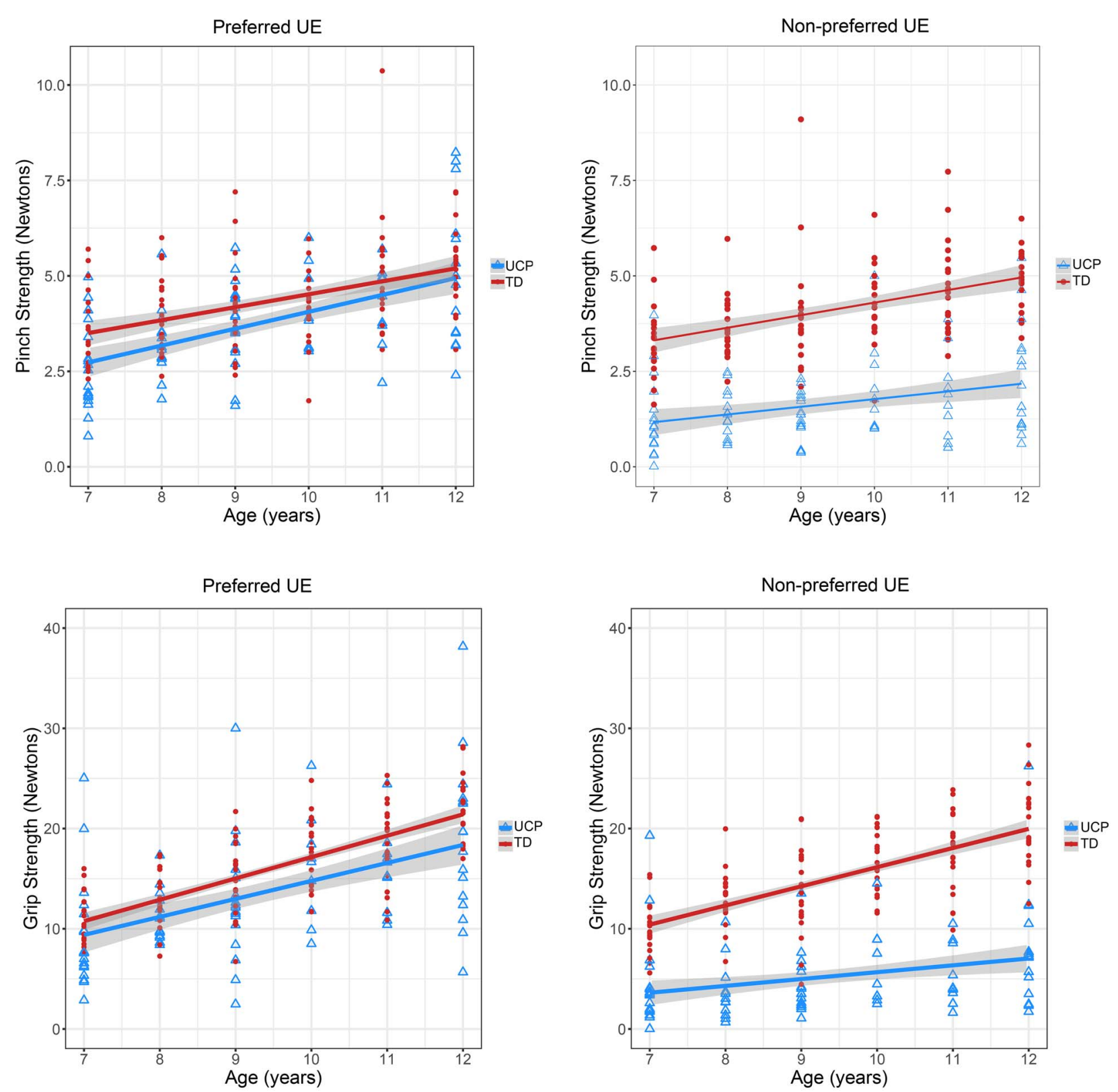

Figure 2.

Differences in grip strength between TD children and children with USCP.

children. Important patient characteristics, such as weight, height, and age, did not differ significantly between the 2 groups; therefore, the possible influence of country of residence is likely to be minimal. However, because most participants were Dutch, it is unknown if the differences in muscle strength are generalizable to populations with a lower or higher percentage of overweight or obese children.

We tried to have all therapists testing both the children with USCP and children with TD, but unfortunately this was not always possible for practical reasons. Therefore, personal measurement errors could have influenced the results. However, the measurement therapists also participated in a reliability study and showing excellent reliability ${ }^{32}$ indicating that they were likely sufficiently trained and consistent.

Although we already included more participants than most other studies on this topic, more participants are needed to be able to better differentiate which variables 
differs most between groups. Therefore, the results must be interpreted with some caution. A more global collaboration is needed to produce studies with a larger sample size.

In children with USCP, muscle weakness in both UEs occurs. When unimanual or bimanual ability limitations are present, investigation of muscle strength in the nonaffected UE should be part of the assessment. Future research should focus on whether particular characteristics related to children with USCP can explain these differences in muscle strength and whether and where muscle weakness is present in the UE in adolescents with USCP.

\section{Author Contributions and Acknowledgments}

Concept/idea/research design: K.J.F.M. Dekkers, E.A.A. Rameckers, R.J.E.M. Smeets, Y.J.M. Janssen-Potten

Writing: K.J.F.M. Dekkers, E.A.A. Rameckers, R.J.E.M. Smeets, C.L. Ferre, Y.J.M. Janssen-Potten, A.M. Gordon, L.A.W.M. Speth Data collection: K.J.F.M. Dekkers, E.A.A. Rameckers, A.M. Gordon, L.A.W.M. Speth

Data analysis: K.J.F.M. Dekkers, E.A.A. Rameckers, R.J.E.M. Smeets, C.L. Ferre, Y.J.M. Janssen-Potten

Project management: K.J.F.M. Dekkers, E.A.A. Rameckers,

R.J.E.M. Smeets, Y.J.M. Janssen-Potten

Fund procurement: K.J.F.M. Dekkers, E.A.A. Rameckers,

R.J.E.M. Smeets, Y.J.M. Janssen-Potten

Providing participants: K.J.F.M. Dekkers, E.A.A. Rameckers,

A.M. Gordon, L.A.W.M. Speth

Providing facilities/equipment: K.J.F.M. Dekkers, E.A.A. Rameckers, A.M. Gordon, Y.J.M. Janssen-Potten

Providing institutional liaisons: R.J.E.M. Smeets,

Y.J.M. Janssen-Potten

Consultation (including review of manuscript before submitting):

E.A.A. Rameckers, R.J.E.M. Smeets, A.M. Gordon, L.A.W.M. Speth, Y.J.M. Janssen-Potten

The authors express special thanks to all children who participated in this study and to the cooperating schools and rehabilitation centers.

\section{Funding}

This study was supported by Forward for Children With Disabilities Foundation, Johanna Children's Foundation, and Revant Innovation Foundation.

\section{Ethics Approval}

This study was approved by the Medical Ethical Board of Maastricht University Medical Center and Maastricht University (METC azM/UM; trial number NL45430.068.1), the Netherlands, and by Teachers College, Columbia University, New York City, NY.

\section{Disclosures}

The authors completed the ICMJE Form for Disclosure of Potential Conflicts of Interest and reported no conflicts of interest.

DOI: $10.1093 / p t j / p z a a 155$

\section{References}

1 Cans C. Surveillance of cerebral palsy in Europe: a collaboration of cerebral palsy surveys and registers. Dev Med Child Neurol. 2000;42:816-824.

2 Types of cerebral palsy. Cerebral Palsy Alliance website. 2018. Accessed August 12, 2020. https://research.cerebralpalsy.o rg.au/what-is-cerebral-palsy/types-of-cerebral-palsy/

3 Types of CP. Cerebral Palsy Foundation website. 2020. Accessed August 12, 2020. http://yourcpf.org/types-of-cp/

4 Vaz DV, Cotta M, Fonseca ST, De Melo Pertence AE. Muscle stiffness and strength and their relation to hand function in children with hemiplegic cerebral palsy. Dev Med Child Neurol. 2006;48:728-733.

5 Smits-Engelsman B, Rameckers E, Duysens J. Muscle force generation and force control of finger movements in children with spastic hemiplegia during isometric tasks. Dev Med Child Neurol. 2005;47:337-342.

6 Klingels K, Demeyere I, Jaspers E, et al. Upper limb impairments and their impact on activity measures in children with unilateral cerebral palsy. Eur J Paediatr Neurol. 2012;16: 475-484.

7 Braendvik SM, Elvrum AK, Vereijken B, Roeleveld K. Relationship between neuromuscular body functions and upper extremity activity in children with cerebral palsy. Dev Med Child Neurol. 2010;52:e29-e34.

8 Okumura A, Kato T, Kuno K, Hayakawa F, Watanabe K. MRI findings in patients with spastic cerebral palsy, II: correlation with type of cerebral palsy. Dev Med Child Neurol. 1997;39: 369-372.

9 Niemann G, Wakat JP, Krageloh-Mann I, Grodd W, Michaelis R. Congenital hemiparesis and periventricular leukomalacia: pathogenetic aspects on magnetic resonance imaging. Dev Med Child Neurol. 1994;36:943-950.

10 Scheck SM, Fripp J, Reid L, et al. Extent of altered white matter in unilateral and bilateral periventricular white matter lesions in children with unilateral cerebral palsy. Res Dev Disabil. 2016;55:368-376.

11 Scheck SM, Pannek K, Fiori S, Boyd RN, Rose SE. Quantitative comparison of cortical and deep grey matter in pathological subtypes of unilateral cerebral palsy. Dev Med Child Neurol. 2014;56:968-975.

12 Rich TL, Menk JS, Rudser KD, Feyma T, Gillick BT. Less-affected hand function in children with hemiparetic unilateral cerebral palsy: a comparison study with typically developing peers. Neurorehabil Neural Repair. 2017;31: 965-976.

13 Filho GN, Souza L, Nunes LG, Braga LW, Dellatolas G. Manual skill, hand skill asymmetry, and neuropsychological test performance in schoolchildren with spastic cerebral palsy. Laterality. 2005;10:161-182.

14 Tomhave WA, Van Heest AE, Bagley A, James MA. Affected and contralateral hand strength and dexterity measures in children with hemiplegic cerebral palsy. J Hand Surg. 2015; 40:900-907.

15 Basu AP, Kirkpatrick EV, Wright B, Pearse JE, Best KE, Eyre JA. The Tyneside pegboard test: development, validation, and observations in unilateral cerebral palsy. Dev Med Child Neurol. 2018;60:314-321.

16 Wyke M. Effect of brain lesions on the rapidity of arm movement. Neurology. 1967;17:1113-1120. 
17 Winstein C, Pohl P. Effects of unilateral brain damage on the control of goal-directed hand movements. Exp Brain Res. 1995; 105:163-174.

18 Haaland KY, Prestopnik JL, Knight RT, Lee RR. Hemispheric asymmetries for kinematic and positional aspects of reaching. Brain. 2004;127:1145-1158.

19 Bohannon RW, Andrews AW. Limb muscle strength is impaired bilaterally after stroke. J Phys Ther Sci. 1995;7:1-7.

20 Schaefer SY, Haaland KY, Sainburg RL. Ipsilesional motor deficits following stroke reflect hemispheric specializations for movement control. Brain. 2007;130:2146-2158.

21 Yarosh CA, Hoffman DS, Strick PL. Deficits in movements of the wrist ipsilateral to a stroke in hemiparetic subjects. $J$ Neurophysiol. 2004;92:3276-3285.

22 Sainburg RL, Maenza C, Winstein C, Good D. Motor lateralization provides a foundation for predicting and treating non-paretic arm motor deficits in stroke. Adv Exp Med Biol. 2016;957:257-272.

23 Colebatch JG, Gandevia S. The distribution of muscular weakness in upper motor neuron lesions affecting the arm. Brain. 1989;112:749-763.

24 Wetter S, Poole JL, Haaland KY. Functional implications of ipsilesional motor deficits after unilateral stroke. Arch Phys Med Rehabil. 2005;86:776-781.

25 Sainburg RL, Duff SV. Does motor lateralization have implications for stroke rehabilitation? J Rehabil Res Dev. 2006; $43: 311-322$

26 Desrosiers J, Bourbonnais D, Bravo G, Roy P-M, Guay M. Performance of the 'unaffected' upper extremity of elderly stroke patients. Stroke. 1996;27:1564-1570.

27 Bohannon RW. Muscle strength and muscle training after stroke. J Rehabil Med. 2007;39:14-20.

28 Harris JE, Eng JJ. Paretic upper-limb strength best explains arm activity in people with stroke. Phys Ther. 2007;87:88-97.

29 Ada L, Dorsch S, Canning CG. Strengthening interventions increase strength and improve activity after stroke: a systematic review. Aust J Physiother. 2006;52:241-248.

30 Pagliano E, Andreucci E, Bono R, Semorile C, Brollo L, Fedrizzi E. Evolution of upper limb function in children with congenital hemiplegia. Neurol Sci. 2001;22:371-375.

31 Fedrizzi E, Pagliano E, Andreucci E, Oleari G. Hand function in children with hemiplegic cerebral palsy: prospective follow-up and functional outcome in adolescence. Dev Med Child Neurol. 2003;45:85-91.

32 Dekkers K, Janssen-Potten Y, Gordon AM, Speth L, Smeets R, Rameckers E. Reliability of maximum isometric arm, grip and pinch strength measurements in children (7-12 years) with unilateral spastic cerebral palsy. Disabil Rehabil. 2020;42: 1448-1453.

33 Palisano R, Rosenbaum P, Walter S, Russell D, Wood E, Galuppi B. Development and reliability of a system to classify gross motor function in children with cerebral palsy. Dev Med Child Neurol. 1997;39:214-223.

34 Eliasson AC, Krumlinde-Sundholm L, Rösblad B, et al. The manual ability classification system (MACS) for children with cerebral palsy: scale development and evidence of validity and reliability. Dev Med Child Neurol. 2006;48:549-554.

35 Mayhew T, Rothstein JM. Measurement of muscle performance with instruments. In: Rothstein JM, ed. Measurement in Physical Therapy. New York, NY: Churchill Livingstone Inc; 1985: 57-102.

36 Becher J, Pangalila R, Vermeulen R, Van Barneveld T, Raats C. Richtlijn diagnostiek en behandeling van kinderen met spastische cerebrale parese. [Guideline for diagnosis and treatment of children with spastic cerebral palsy]. Utrecht, the Netherlands: Nederlandse Vereniging van

Revalidatieartsen [Dutch Association of Rehabilitation Physicians]; 2006.

37 Ferreira ACC, Shimano AC, Mazzer N, Barbieri CH, Elui VMC Fonseca MCR. Grip and pinch strength in healthy children and adolescents. Acta Ortop Bras. 2011;19:92-97.

38 Ervin RB, Fryar CD, Wang C-Y, Miller IM, Ogden CL. Strength and body weight in US children and adolescents. Pediatrics. 2014;134:e782-e789.

39 Duncan S, Duncan EK, Fernandes RA, et al. Modifiable risk factors for overweight and obesity in children and adolescents from Sao Paulo, Brazil. BMC Public Health. 2011;11:585.

40 Overgewicht cijfers (overweight/problem sketch/facts). Nederlands Jeugdinstituut (Dutch Youth Institute) website. 2019. Accessed August 12, 2020. https://www.nji.nl/Overgewi cht-Probleemschets-Cijfers

41 Staudt M, Grodd W, Gerloff C, Erb M, Stitz J, Krageloh-Mann I. Two types of ipsilateral reorganization in congenital hemiparesis: a TMS and fMRI study. Brain. 2002;125: 2222-2237. 